\title{
Studies on the mechanism of inhibition of chemotactic tripeptide stimulated human neutrophil polymorphonuclear leucocyte superoxide production by chloroquine and hydroxychloroquine
}

\author{
N P HURST, J K FRENCH, L GORJATSCHKO, AND W H BETTS \\ From the Combined Royal Adelaide and Queen Elizabeth Hospital Rheumatology Unit, Queen Elizabeth \\ Hospital, Woodville, South Australia
}

SUMmaRY The effect of chloroquine and hydroxychloroquine on neutrophil superoxide release stimulated by the chemotactic tripeptide $N$-formyl-methionyl-leucyl-phenylalanine (FMLP) was ${ }^{\circ}$ examined. Both drugs caused time and dose dependent inhibition of superoxide release but had $ᄋ$ no effect on equilibrium binding of $\left[{ }^{3} \mathrm{H}\right]$ FMLP to its receptor. Preliminary experiments suggest $\rightarrow$ that these drugs may exert their inhibitory effect on superoxide release by inhibiting the FMLPO stimulated hydrolysis of phosphoinositides.

Chloroquine (CQ), hydroxychloroquine (HCQ), and previously mepacrine have been widely used in the treatment of rheumatoid arthritis and systemic lupus erythematosus. ${ }^{1}$ They have both immunosuppressive and anti-inflammatory effects, ${ }^{12}$ which may be mediated by inhibition of polymorphonuclear (PMN) and mononuclear phagocyte function. ${ }^{134}$ Both these cell types are intimately involved in the pathogenesis of inflammatory arthritis.

Inhibitory effects of these drugs on phagocyte function have been attributed to their lysosomotropism, which results in inhibition of lysosomal functions, including lysosomal enzyme release, receptor recycling, lysosomal digestion, and metabolism of lipids. ${ }^{1}$ They also inhibit non-lysosomal functions, including cytokine release ${ }^{2}$ and chemotaxis. ${ }^{3} \mathrm{We}$ have recently reported that these drugs have differential effects on other non-lysosomal aspects of blood monocyte metabolism and function, including superoxide production, phospholipid methylation, and arachidonic acid (AA) release. ${ }^{4}$ We have extended these studies to examine the effect of $\mathrm{CQ}$ and HCQ on PMN superoxide release stimulated by the chemotactic tripeptide, $N$-formyl-methionylleucyl-phenylalanine (FMLP).

We report here that these agents inhibit FMLP stimulated superoxide release without affecting

Accepted for publication 12 April 1987.

Correspondence to Dr N P Hurst, The Queen Elizabeth Hospital, Woodville, South Australia 5011.
FMLP-receptor binding. Our data suggest that inhibition of superoxide release may in part be de to inhibition of FMLP-receptor induced hydrolysits of membrane phosphoinositides.

\section{Materials and methods}

M A T E R I A L S

FMLP, CQ, catalase, cytochalasin B, and diacyl-3 glycerol were obtained from Sigma (St Louis, MO); HCQ was a gift from Sterling-Winthrop Rensselaer, $\mathrm{NY} ;\left[{ }^{3} \mathrm{H}\right] \mathrm{AA} \quad(4.7 \mathrm{TBq} / \mathrm{mmol}),\left[{ }^{3} \mathrm{H}\right]$ FMLP $(1.85 \stackrel{0}{0}$ $\mathrm{TBq} / \mathrm{mmol}$ ) were from New England Nuclear, Boston, MA; cytochrome $c$ was from Boehringer Mannheim Penzberg, FDR.

PREPARATION OF CELL SUSPENSIONS Polymorphonuclear leucocytes (PMN) were sepa-응 rated from peripheral blood obtained from normal $>$ healthy volunteers, on a double Percoll gradient as으․ previously described. ${ }^{5}$ PMN were suspended in indicator free Hanks's balanced salt solution(HBSS) ( $\mathrm{pH} \mathrm{7.4)}$ and the cell concentration ad- $N$ justed to $10^{6}$ cells $/ \mathrm{ml}$. Except where stated, incuba- N tions were performed in serum free media.

PREPARATION OF STIMULI

A stock solution of $20 \mathrm{mM}$ FMLP was prepared in dimethyl sulphoxide (DMSO), stored at $4^{\circ} \mathrm{C}$, and 0 diluted with Dulbecco's phosphate buffered saline $\overline{{ }^{\circ}}$ (DPBS) to $10 \mu \mathrm{mol} / 1$ immediately before use. The 
final concentrations of DMSO did not exceed $0 \cdot 1 \%$ and had no effect on the release or detection of superoxide. A stock solution of sodium fluoride (200 $\mathrm{mM}$ ) was prepared in distilled water.

\section{MEASUREMENT OF SUPEROXIDE PRODUCTION}

Superoxide production was measured by reduction of cytochrome $c$ using an extinction coefficient $(550-540 \mathrm{~nm})$ of $21 \cdot 1 \mathrm{mmol}^{-1} \cdot \mathrm{cm}^{-1} \cdot{ }^{6} \mathrm{PMN}(700 \mu \mathrm{l})$ were preincubated at $37^{\circ} \mathrm{C}$ for designated times up to 60 minutes with $100 \mu \mathrm{l}$ of either buffer or the appropriate concentration of $\mathrm{CQ}$ or $\mathrm{HCQ}$ before addition of $100 \mu \mathrm{l}$ cytochrome $c(100 \mu \mathrm{mol} / \mathrm{l}$ final concentration) and appropriate stimulus $(100 \mu \mathrm{l})$. Cells were then stimulated with either FMLP $(0.2 \mu \mathrm{M})$ or fluoride $(20 \mathrm{mM})$ for varying times as indicated. Each experiment was performed in quadruplicate (unless otherwise stated). Where indicated, continuous time course experiments were performed on a Varian DMS-100 double beam spectrophotometer attached to a Varian DS-15 computer. Each test cuvette was monitored at 550 $\mathrm{nm}$ and $540 \mathrm{~nm}$. Results of inhibitory studies are expressed as a percentage of the control value (no drug added). Cell viability was confirmed to be $>95 \%$ by trypan blue exclusion.

MEASUREMENT OF $\left[{ }^{3} \mathrm{H}\right]$ FMLP BINDING Incubations were performed in quintuplicate at $37^{\circ} \mathrm{C}$ in 96 well filtration plates manufactured with an intregral $5 \mu \mathrm{m}$ pore size filter at the bottom of each well (Millipore, STGV 09610). The plates were precoated with unlabelled FMLP, then washed and dried at $37^{\circ} \mathrm{C}$. A stock solution of $\left[{ }^{3} \mathrm{H}\right] \mathrm{FMLP}(2 \mu \mathrm{M}$; $0.37 \mathrm{TBq} / \mathrm{mmol}$ ) was prepared by diluting $\left[{ }^{3} \mathrm{H}\right]$ FMLP $(1.85 \mathrm{TBq} / \mathrm{mmol})$ with unlabelled FMLP in TRIS (trometamol) buffer. PMN $\left(10^{6}\right)$ in $80 \mu$ of TRIS buffer (100 mM TRIS; $1.6 \mathrm{mM} \mathrm{CaCl} 2 ; \mathrm{pH}$ adjusted to 7.2 with $\mathrm{HCl}$ ) were incubated for $30 \mathrm{~min}$ with $10 \mu \mathrm{l}$ of buffer or drug solution. Then $5 \mu \mathrm{l}$ of a stock solution containing $10 \mathrm{mM} \mathrm{NaN}_{3}, 11000 \mathrm{U} / \mathrm{ml}$ catalase, and $5 \mu \mathrm{g} / \mathrm{ml}$ cytochalasin $B$ was added to all wells followed by $5 \mu$ of stock $\left[{ }^{3} \mathrm{H}\right]$ FMLP $(7 \cdot 4 \mathrm{kBq})$. Non-specific binding was determined by the addition of a 1000-fold excess of unlabelled FMLP to quintuplicate control wells.

The cells were incubated for a further $30 \mathrm{~min}$ and then washed five times with DPBS containing $0 \cdot 01$ M TRIS at $\mathrm{pH} 7 \cdot 2$. Washing was performed by placing the Millipore plate over a vacuum manifold (Millipore, XX2809600) which draws the supernatant through the bottom of each well. Further buffer was added to the wells for each wash. After washing, the plate was dried at $37^{\circ} \mathrm{C}$, the filter from each well was cut out, and the bound $\left[{ }^{3} \mathrm{H}\right] \mathrm{FMLP}$ measured by liquid scintillation counting.

MEASUREMENT OF DIACYLGLYCEROL

RE LEA S E

PMN $\left(10^{6} / \mathrm{ml}\right)$ in DPBS were labelled for $30 \mathrm{~min}$ with $\left[{ }^{3} \mathrm{H}\right] \mathrm{AA}\left(74 \mathrm{kBq} / 10^{7} \mathrm{PMN}\right)$, washed twice with DPBS, and resuspended in HBSS. Incorporation of label into phosphatidylcholine and phosphatidylinositol was confirmed by thin layer chromatographic (TLC) analysis of phospholipids. ${ }^{7}$ After labelling, PMN were then stimulated with FMLP for the designated time, the reaction terminated with $10 \%$ trichloroacetic acid, and lipids extracted with $5 \mathrm{ml}$ chloroform/methanol $(2 / 1, \mathrm{v} / \mathrm{v})$. The lipid extract $(3$ $\mathrm{ml})$ was dried under nitrogen and subjected to TLC analysis on silica gel 60 (Merck 5721) with hexane/ ether/methanol/acetic acid $(80 / 21 / 4 \cdot 5 / 2, \mathrm{v} / \mathrm{v})$ as mobile phase. ${ }^{8}\left[{ }^{3} \mathrm{H}\right]$ Diacylglycerol (DG) was identified using authentic standards and measured by scintillation counting.

I N C U B A TION CONDITIONS

Earlier studies had shown the time dependence of uptake of CQ and HCQ by PMN, and had established that incubation with up to $0.1 \mathrm{mmol} / \mathrm{l}$ concentration of either drug for 60 minutes, in the absence of serum, results in intracellular concentrations of CQ and HCQ comparable with those found during therapy. ${ }^{9}$ In these studies, therefore, maximal incubation times and drug concentrations did not exceed $60 \mathrm{~min}$ or $0.1 \mathrm{mmol} / \mathrm{l}$ respectively. In some experiments the effect of including $5 \%$ fetal calf serum (FCS) in the incubation medium was examined.

\section{Results}

EFFECT OF CQ AND HCQ ON SUPEROXIDE PRODUCTION STIMULATED BY FMLP

Initial experiments were performed in HBSS without added FCS. Both CQ and HCQ caused dose dependent inhibition of PMN superoxide release stimulated by FMLP with a similar inhibitory dose response profile after 30 or 60 min preincubation with either drug (Fig. 1). Further examination showed there to be a similar degree of inhibition after preincubation of cells with $10^{-4} \mathrm{M} \mathrm{CQ}$ or $\mathrm{HCQ}$ for either 0,30 , or $60 \mathrm{~min}$. When $5 \%$ FCS was included in the medium, however, the effect of $\mathrm{CQ}$ became clearly time dependent (Fig. 2).

Kinetic studies showed that $\mathrm{CQ}$ and $\mathrm{HCQ}$ inhibited both the initial rate and total superoxide production stimulated by FMLP (Fig. 3).

Neither drug affected unstimulated basal PMN 


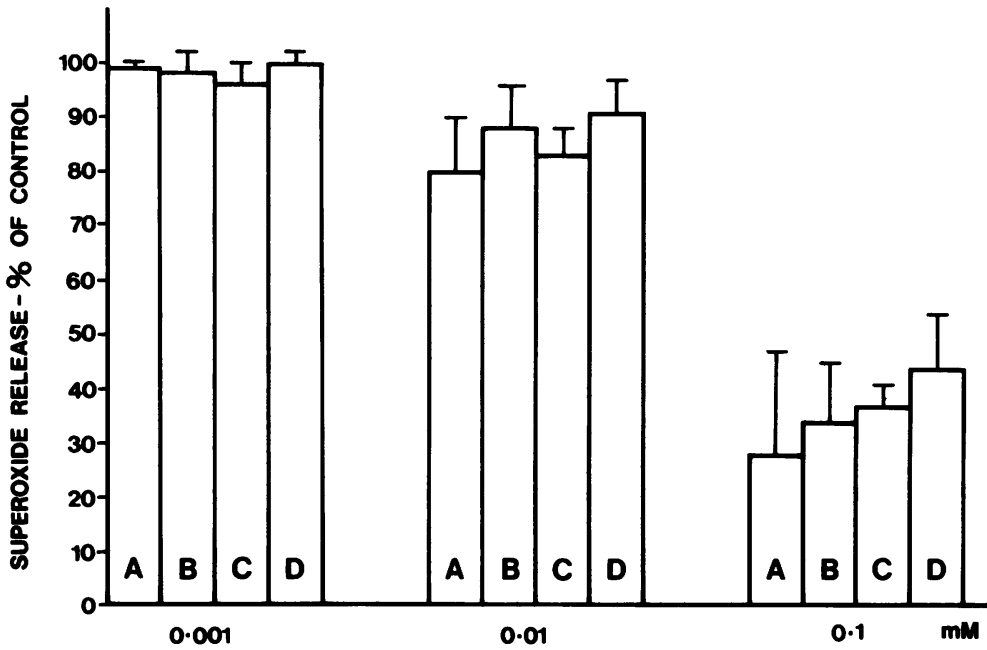

Fig. 1 Total PMN superoxide release stimulated by FMLP for 10 min after preincubation for 60 min with $(A) C Q$ or

(C) $H C Q \quad(n=3)$, or for $30 \mathrm{~min}$ with (B) CQ or (D) HCQ (n=5).

Results expressed as percentage $\overrightarrow{0}$ of control (mean (SEM)). Meansuperoxide release in controls:

(A) 11, (B) 13, (C) 9,

(D) $8 \mathrm{nmol} / 10^{6}$. PMN.

CONCENTRATION OF DRUG

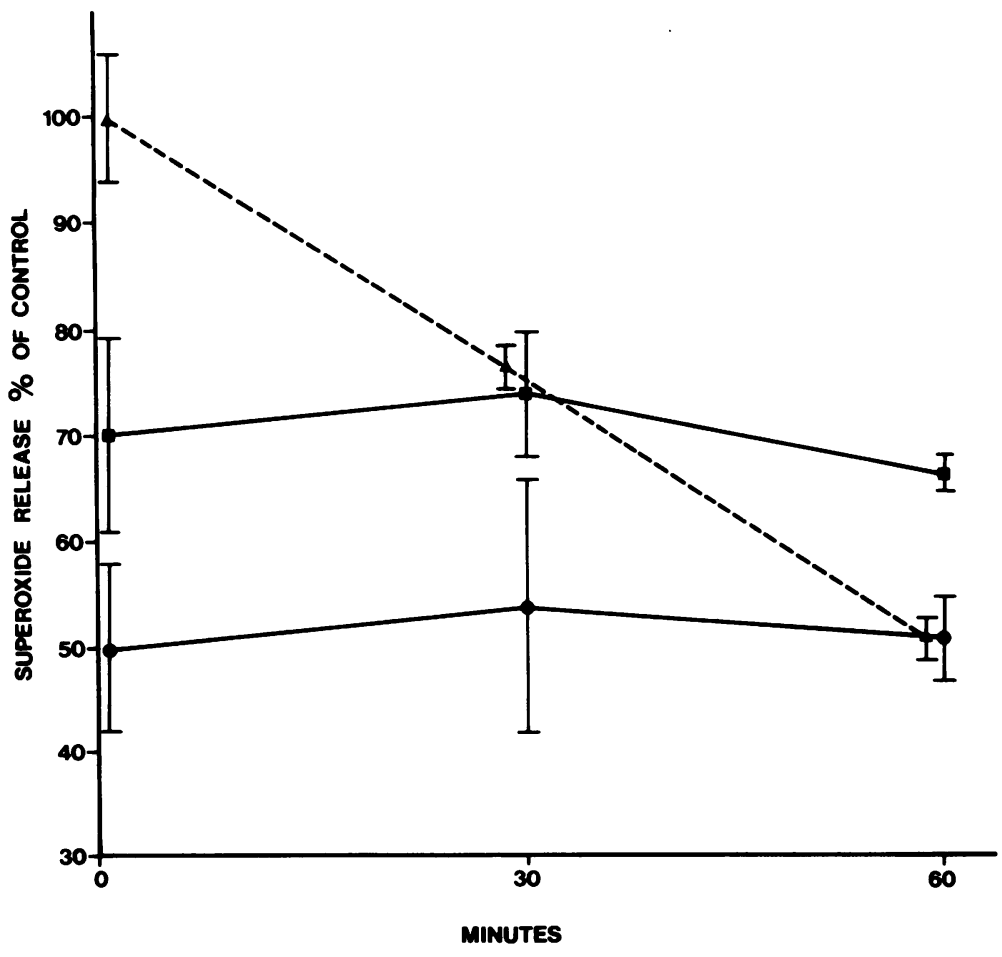

Fig. 2 Total PMN superoxide release stimulated by FMLP for 10 min after preincubation for 0,30 , or 60 min with either $10^{-4}$ $M C Q(O)$ or $H C Q$ (口) in the $\stackrel{\mathbb{Q}}{\square}$ absence of FCS, or with $10^{-4}$ $M C Q(\Delta)$ in the presence of FCS Results expressed as percentage of control (mean (SEM)). Mean superoxide release in controls at 0,30 , and $60 \mathrm{~min}$ was (O) 10, 9, and $6 \mathrm{nmol} / 10^{6} \mathrm{PMN}$; (口) 12,10 , and $8 \mathrm{nmol} / 10^{\circ} \mathrm{PMN}$; and $(\Delta)$ 15, 18, and $18 \mathrm{nmol} / 10^{6} \mathrm{PMN}$.

superoxide release measured over 15 minutes (not shown).

EFFECT OF CQ AND HCQ ON FMLP-RECEPTOR B I N D I N G

The effect of CQ and HCQ on the equilibrium binding of $\left[{ }^{3} \mathrm{H}\right]$ FMLP to PMN at $37^{\circ} \mathrm{C}$ was examined. Time course studies of binding of $\left[{ }^{3} \mathrm{H}\right]$ FMLP (Fig. 4) showed that equilibrium was reached by 30 minutes but that some slow loss of binding occurred thereafter; similar results have ${ }_{0}^{-}$ been reported previously. ${ }^{10}$ Preincubation of PMN 


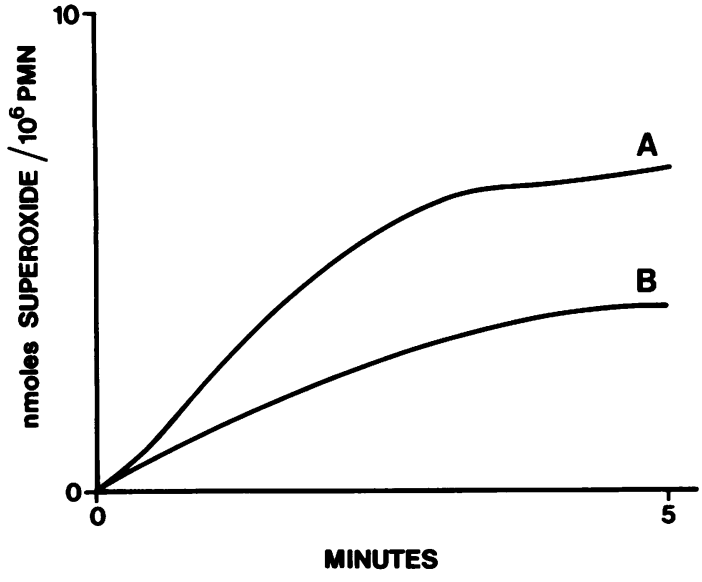

Fig. 3 Kinetics of PMN superoxide production stimulated by FMLP after 30 min preincubation $(A)$ without or (B) with $10^{-4} M C Q$. One representative result from three separate experiments. Similar results were obtained with $H C Q$ (not shown). with either drug for 30 minutes, followed by incubation with $\left[{ }^{3} \mathrm{H}\right] \mathrm{FMLP}$ for a further $30 \mathrm{~min}$ had no significant effect on either total, specific, or nonspecific binding of $\left[{ }^{3} \mathrm{H}\right]$ FMLP to PMN (Table 1).

Table 1 Effect of $C Q$ and $H C Q$ on $\left[{ }^{3} H\right] F M L P$ binding to $P M N$

\begin{tabular}{|c|c|c|c|c|c|}
\hline & \multirow[t]{2}{*}{$n$} & & \multicolumn{3}{|c|}{$\begin{array}{l}\left.\text { Inhibition of } l^{3} H\right] F M L P \text { binding } \\
\quad(\% \text { of control })\end{array}$} \\
\hline & & & $1 \mu M$ & $10 \mu M$ & $100 \mu M$ \\
\hline HCQ & 3 & $\begin{array}{l}\text { Total } \\
\text { Non-specific } \\
\text { Specific }{ }^{*}\end{array}$ & $\begin{array}{l}100(6) \\
115(10) \\
104(14)\end{array}$ & $\begin{array}{l}93(3) \\
92(4) \\
92(6)\end{array}$ & $\begin{array}{l}97(3) \\
99(5) \\
94(5)\end{array}$ \\
\hline $\mathrm{CQ}$ & 4 & $\begin{array}{l}\text { Total } \\
\text { Non-specific } \\
\text { Specific } \dagger\end{array}$ & $\begin{array}{r}92(7) \\
104(6) \\
88(14)\end{array}$ & $\begin{array}{r}98(3) \\
108(2) \\
95(7)\end{array}$ & $\begin{array}{r}92(5) \\
106(3) \\
85(9)\end{array}$ \\
\hline
\end{tabular}

Mean specific binding was ${ }^{*} 23(4)$ and $\nmid 21 \cdot 3(6)$ fmol $/ 10^{6}$ PMN. Results expressed as percentage of control (mean (SEM)) (no drug added). $n=$ number of separate experiments.

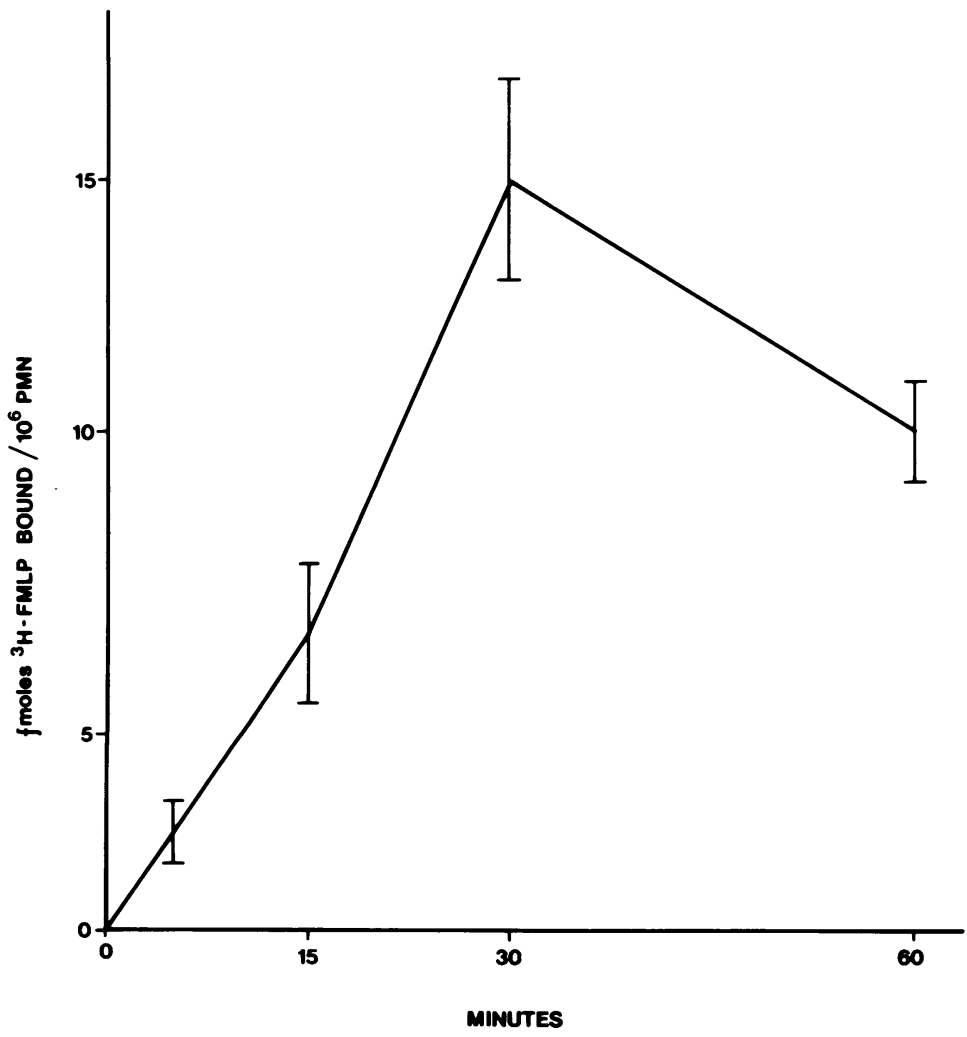

Fig. 4 Time course of $\left.{ }^{3} \mathrm{H}\right] \mathrm{FMLP}$ binding to PMN. Each point represents mean (SEM) (quintuplicates). One representative result from three separate experiments. 


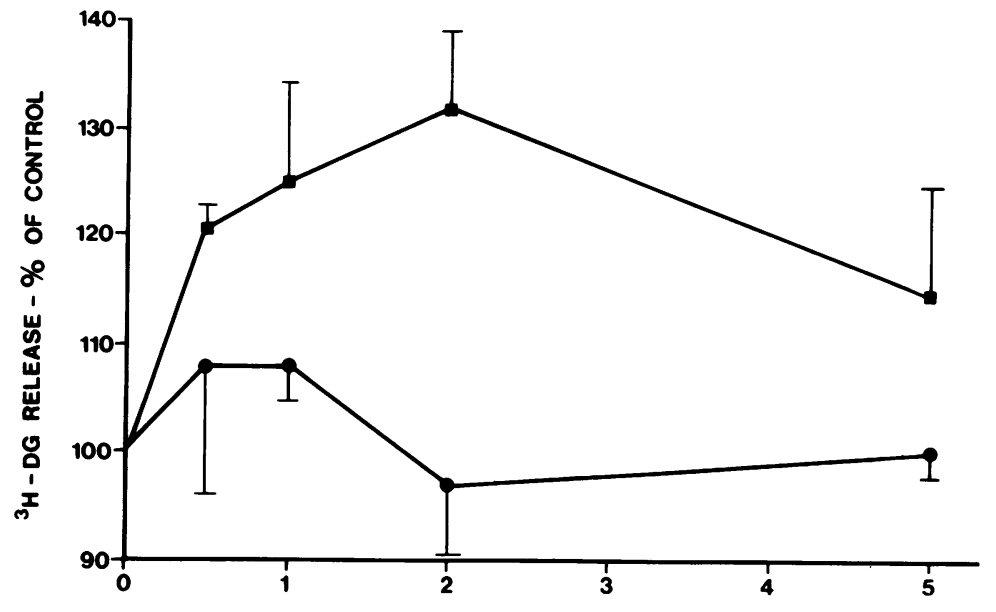

Fig. 5 Time course of $\left[^{3} \mathrm{H}\right]$ diacylglcerol $(D G)$ production by $P M N$ in the presence (ם) or absence (O) of FMLP. Non-specific background release of $\left[{ }^{3} \mathrm{H}\right] \mathrm{DG}$ at $t=0 \mathrm{~min}$ was $5000 \pm 350 \mathrm{dpm}$. For convenience this background value is expressed as $100 \%$ and additional release after stimulation by FMLP is expressed as a percentage increase over this control value. Each point represents mean (SEM) of two experiments each performed

MINUTES
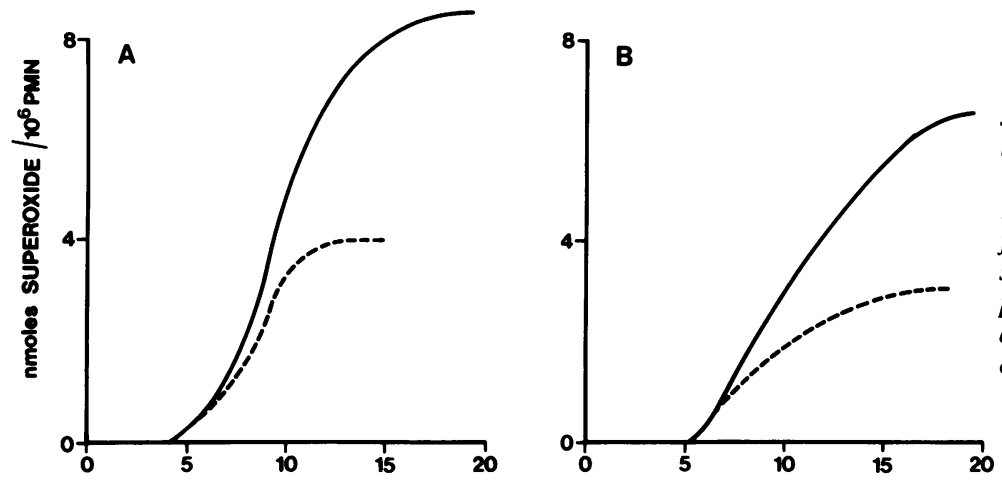

Fig. 6 Kinetics of PMN superoxide production stimulated by fluoride after (A) $10 \mathrm{~min}$ or (B) 30 min preincubation with $10^{-4} \mathrm{M} C Q$. One typical result from four separate experiments is shown. In one experiment prolongation of the lag time was also noted. Similar results were obtained with HCQ (not shown).

EFFECT OF CQ ON DIACYLGLYCEROL RELEASE STIMULATED BY FMLP

Time course studies showed that maximal DG release occurred by two minutes and then declined (Fig. 5). The amount of $\left[{ }^{3} \mathrm{H}\right] \mathrm{DG}$ release after stimulation by FMLP varied between experiments, and background levels of non-stimulated $\left[{ }^{3} \mathrm{H}\right] \mathrm{DG}$ release were high. After $30 \mathrm{~min}$ incubation with $10^{-4} \mathrm{M} \mathrm{CQ}, \mathrm{DG}$ release (mean (SEM)) after two minutes stimulation by FMLP was reduced by 89 (10)\% $(n=3) \quad(p=0.05$; paired Student's $t$ test, calculated from dpm $\left.\left[{ }^{3} \mathrm{H}\right] \mathrm{DG}\right)$. In each of these three experiments parallel studies of superoxide release were performed which showed inhibition of superoxide release by $47(10) \%(p<0.02$; paired Student's $t$ test, calculated from nmoles superoxide).
The difference between the mean percentage inhibi tion of DG release and superoxide production was not statistically significant ( $\mathrm{p}>0 \cdot 1$, Student's $t$ test) $\stackrel{\circ}{\square}$

EFFECT OF CQ AND HCQ ON SUPEROXIDE RELEASE STIMULATED BY FLUORIDE

Both $\mathrm{HCQ}$ and $\mathrm{CQ}\left(10^{-4} \mathrm{M}\right)$ inhibited superoxide release stimulated by fluoride. Both drugs inhibited the maximum rate and the total amount of superox $N$ ide released (Fig. 6), but in some experiments thereo was also prolongation of the lag time.

\section{Discussion}

The metabolic pathways which link FMLP-receptoro stimulation with activation of the phagocyt NADPH oxidase remain uncertain. Current evi 
dence suggests that occupied FMLP receptors stimulate phosphoinositidase C (PIC) dependent hydrolysis of membrane phosphatidylinositol bisphosphate to release two second messengers, inositol trisphosphate $\left(\mathrm{IP}_{3}\right)$ and DG. ${ }^{11}{ }^{12}$ FMLP also stimulates the phospholipase D mediated hydrolysis of phosphatidylinositol to phosphatidic acid, which is further metabolised to DG. ${ }^{11}$ Release of $\mathrm{IP}_{3}$ and DG derived via the PIC route is rapid and a function of receptor occupancy, whereas DG from the phospholipase $\mathrm{D}$ route occurs after a short lag and is sustained for at least two minutes. ${ }^{11} \mathrm{IP}_{3}$ is believed to stimulate release of calcium from internal stores, ${ }^{13}$ which then acts synergistically with DG to activate a phospholipid/calcium dependent protein kinase (protein kinase C) (PKC). ${ }^{14}$ Current evidence suggests that this kinase phosphorylates and activates the flavoprotein component of the NADPH oxidase. ${ }^{15}$ 16 The involvement of other metabolic pathways, independent of protein kinase $C$, in activation of the PMN respiratory burst by FMLP is also suggested by recent reports. ${ }^{17} 18$ In the experiments reported here we have examined the effect of CQ and HCQ on activation of the PMN respiratory burst by FMLP.

Both drugs inhibited superoxide release stimulated by FMLP in a dose dependent fashion. This effect was rapid and not demonstrably time dependent unless FCS was included in the medium. This presumably reflects binding of CQ by FCS, which would tend to slow the rate of partitioning of $\mathrm{CQ}$ between cellular and extracellular compartments. In previous studies we have shown that the accumulation of antimalarials within PMN in the absence of serum is time dependent. ${ }^{9}$ Thus the very rapid inhibitory effect of both drugs in the absence of serum suggests a direct effect on the plasma membrane which does not require significant accumulation within intracellular compartments such as lysosomes.

The effect of CQ and HCQ on superoxide release stimulated by FMLP could be due to several possible mechanisms, including inhibition of $(a)$ receptor-ligand binding, $(b)$ phosphoinositide hydrolysis, (c) translocation and activation of PKC, or (d) translocation or activation of the NADPH oxidase, or both.

Studies of the effect of CQ and HCQ on superoxide release stimulated by fluoride were performed in an attempt to exclude a direct effect of these drugs on the NADPH oxidase. We have previously reported that neither drug inhibits fluoride stimulated monocyte superoxide production, ${ }^{4}$ suggesting that they have no direct inhibitory effect on the monocyte NADPH oxidase. Both drugs, however, caused a variable degree of inhibition of fluoride mediated superoxide release in PMN. Thus we cannot exclude a direct effect on the NADPH oxidase in PMN. Though possible, it is unlikely that this enzyme is innibitable by CQ or HCQ in one cell type and not another. It is more likely that the inhibition observed in PMN reflects a difference in the activation mechanisms of these two cell types. For example, recruitment of oxidase located in specific granules is reported to occur in PMN but not in monocytes ${ }^{19}$; this process could therefore be a target for inhibition by CQ and HCQ, which would explain their different effects on the PMN and monocyte response to fluoride. Further studies will be needed to clarify this point.

Neither drug affected the equilibrium binding of $\left[{ }^{3} \mathrm{H}\right]$ FMLP to its receptor, suggesting that neither the numbers nor the affinity of binding of these receptors had been altered. Thus inhibition of superoxide release induced by FMLP must occur at a site distal to the receptor but proximal to the NADPH oxidase.

To investigate the possibility that $\mathrm{CQ}$ (or HCQ) inhibit the FMLP stimulated hydrolysis of phosphoinositides the effect of CQ on FMLP stimulated DG release was examined. It is important to note that background levels of $\left[{ }^{3} \mathrm{H}\right] \mathrm{AA}$ labelled DG were high and the measured amount of DG released after FMLP stimulation variable and sometimes difficult to detect. These problems have been noted before. ${ }^{11}$ In the presence of CQ $\left(10^{-4}\right.$ M) $\left[{ }^{3} \mathrm{H}\right] \mathrm{DG}$ release stimulated by FMLP was reduced by 89 (SEM 10)\%. These data suggest that 'uncoupling' of receptors from mechanisms of phosphoinositide hydrolysis is one mechanism by which CQ (and presumably HCQ) inhibits FMLP induced superoxide release. The effect of $C Q$ appeared to be greater on DG release than on superoxide production, but the difference was not statistically significant.

The effect of CQ and HCQ on PMN superoxide release stimulated by FMLP is similar to their effect on monocytes. ${ }^{4}$ In these earlier studies on monocytes, however, we did not examine FMLP-receptor binding or phosphoinositide hydrolysis. Although one recent study has shown that $\mathrm{CQ}$ and mepacrine inhibit PMN superoxide release stimulated by zymosan, ${ }^{20}$ there have been no reports to date of the effect of antimalarials on PMN superoxide release stimulated by FMLP.

In conclusion, these studies show that $\mathrm{CQ}$ and HCQ inhibit FMLP stimulated PMN superoxide production without altering FMLP-receptor binding. Our data suggest that these drugs inhibit FMLP stimulated hydrolysis of phosphoinositides, thereby preventing the release of second messengers which mediate intracellular signals leading to activation of 
the NADPH oxidase. These findings give further insight into the mode of action of these drugs and may be relevant to understanding the mechanism of inhibition of other leucocyte functions stimulated by surface receptors.

This work was supported by grants from the NH \& MRC (Australia), Arthritis Foundation of South Australia, and The Queen Elizabeth Hospital Research Foundation. JKF was supported by an NH \& MRC postgraduate medical research scholarship.

\section{References}

1 Mackenzic A $\mathrm{H}$. Pharmacologic actions of 4-aminoquinoline compounds. Am J Med 1983; 75: 5-10.

2 Salmeron G. Lipsky P E. Immunosuppressive potential of antimalarials. Am J Med 1983; 75: 19-24.

3 Ward P A. The chemosuppression of chemotaxis. J Exp Med 1966; 124: 209-25.

4 Hurst N P. French J K. Bell A L. et al. Differential effects of mepacrine. chloroquine and hydroxychloroquine on superoxide anion generation. phospholipid methylation and arachidonic acid relcase by human blood monocytes. Biochem Pharmacol 1986; 35: 3083-9.

5 McColl S R, Betts W H, Murphy G, Cleland L G. Determination of 5-lipoxygenase activity in human polymorphonuclear leukocytes using high-performance liquid chromatography. J Chromatogr 1986; 378: 445-9.

6 Weening R S, Wever R, Roos D. Quantitative aspects of the production of superoxide radicals by phagocytosing human granulocytes. J Lab Clin Med 1975; 85: 245-52.

7 Niwa Y, Sakane T, Taniguchi S. Phospholipid transmethylation in the membrane of human neutrophils and lymphocytes. Arch Biochem Biophys 1984: 234: 7-14.

8 Billah M M. Lapetina E G. Cuatrecasas P. Phospholipase A2 and phospholipase $\mathrm{C}$ activities of platelets. Differential substrate specificity, calcium requirement, $\mathrm{pH}$ dependence and cellular localisation. J Biol Chem 1980; 255: 10227-31.
9 French J K. Hurst N P. O'Donnell M L. Betts W H. Uptake of chloroquine and hydroxychloroquine by human blood leuco cytes in vitro: relation to cellular concentrations during anti? rheumatic therapy. Ann Rheum Dis 1987: 46: 42-5.

10 Niedel J. Wilkinson S. Cuatrecasas P. Receptor-mediated uptake and degradation of ${ }^{125} \mathrm{I}$-chemotactic peptide by humaro neutrophils. J Biol Chem 1979; 254: 10700-6.

11 Cockcroft S. Barrowman M M. Gomperts B D. Breakdown ano synthesis of polyphosphoinositides in fMetLeuPhe-stimulateo neutrophils. FEBS Lett 1985; 181: 259-63.

12 Hurst N P. Molccular basis of activation and regulation of then phagocyte respiratory burst. Ann Rheum Dis 1987; 46: 265-72. Cs

13 Burgess G M, McKinney J S, Irvine R F. Berridge M J, Hoyle $\mathrm{P}_{0}$ C. Putney J W Jr. Inositol 1,4, 5-trisphosphate may be a signaL for f-Met-Leu-Phe-induced intracellular $\mathrm{Ca}$ mobilisation in human leucocytes (HL-60 cells). FEBS Lett 1984; 176: 193-6 -

14 French J K. Hurst N P. Zalewski P D, Valente L, Forbes I Jô Calcium ionophore A23187 enhances human neutrophil super@ oxide release, stimulated by phorbol dibutyrate, by converting phorbol ester receptors from a high to low affinity state. FEB Lett 1987; 212: 242-6.

15 Cross A R. Jones O T G. The effect of the inhibito diphenylene iodonium on the superoxide-generating system of neutrophils. Specific labelling of a component of the oxidase Biochem J 1986; 237: 111-6.

16 Segal A W. Heyworth P G, Cockcroft S. Barrowman M MStimulated neutrophils from patients with autosomal recessivo chronic granulomatous disease fail to phosphorylate Mr-44,000 protein. Nature 1985; 316: 547-9.

17 Wright C D. Hoffman M D. The protein kinase C inhibitors Hळ 7 and $\mathrm{H}-9$ fail to inhibit human neutrophil activation. Biochem Biophys Res Commun 1986; 135: 749-55.

18 Balazovich K J. Smolen J E, Boxer L A. $\mathrm{Ca}^{++}$and p pholipid-dependent protein kinase (protein kinase $\mathrm{C}$ activity not necessarily required for secretion by human neutrop Blood 1986; 68: 810-7.

19 Segal A W. Superoxide generation. cytochrome b245, anc chronic granulomatous disease. In: Weissman G, ed. Advancen in inflammation research. Vol 8. New York: Raven Press, 1984응 $55-83$.

20 Miyachi Y, Yoshioka A. Imamura S. Niwa Y. Antioxidan action of antimalarials. Ann Rheum Dis 1986; 45: 244-8. 